Revista de Derecho

\title{
El efecto de la ineficacia de los actos traslaticios de dominio en el hecho generador del impuesto de alcabala
}

The effect of the inefficacy of ownership transferring contracts on the taxable event of the alcabala tax

\author{
María Bernarda Carpio Frixone \\ Abogada en el Servicio de Rentas Internas \\ Quito, Ecuador \\ mbernarda.carpio@gmail.com \\ ORCID: 0000-0003-1046-0206
}

\section{María Gracia Naranjo Ponce}

Asesora en la Corte Constitucional del Ecuador

Quito, Ecuador

mariagracianaranjo@gmail.com

ORCID: 0000-0002-3132-4230

DOI: https://doi.org/10.32719/26312484.2021.35.9

Fecha de recepción: 20 de mayo de 2020

Fecha de aceptación: 22 de septiembre de 2020

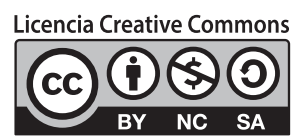




\section{RESUMEN}

A lo largo de este trabajo se realiza una evaluación crítica del art. 529 del Cootad (Código Orgánico de Organización Territorial, Autonomía y Descentralización), el cual prescribe que el impuesto de alcabala pagado como consecuencia de la transferencia de dominio de un bien inmueble no es susceptible de devolución en favor del sujeto pasivo, en los casos de reforma, nulidad, resolución o rescisión de los actos o contratos que precedieron a la transferencia. Específicamente, se analiza el impacto que dichos supuestos de ineficacia tienen en el hecho generador del tributo. El referido análisis se realiza con un enfoque en el rol del principio de capacidad contributiva en el régimen tributario y su incidencia en el hecho generador, a fin de dilucidar si procede desconocer la devolución del impuesto de alcabala en los términos previstos en el art. 529 del Cootad. Se concluye que, en supuestos de nulidad, rescisión o resolución, no existe justificación jurídica para negar la devolución del impuesto de alcabala pagado, en vista de que la consecuencia de estos supuestos de ineficacia es retrotraer los efectos del acto o contrato que originó el cobro del impuesto. En consecuencia, se considera que este efecto retroactivo conlleva a la disolución del hecho generador del tributo, por lo cual negar su devolución contraviene el principio de capacidad contributiva.

PALABRAS CLAVE: alcabala, ineficacia, nulidad, rescisión, resolución, reforma.

\section{ABSTRACT}

This work presents a critical evaluation of article 529 of Cootad (Organic Code of Territorial Organization, Autonomy and Decentralization). Article 529 prescribes that the alcabala tax that has been paid for the transfer of a property will not be refunded in cases of reform, nullity, resolution or rescission of the contracts that preceded the transfer. Specifically, this work analyzes the effect that those cases of inefficacy have over the alcabala tax's taxable event. This analysis is based on the principle of contributory capacity and its incidence over the taxable event of the alcabala tax. It seeks to determine if, in the cases of reform, nullity, resolution or rescission of the acts that preceded the transfer, the taxable event of the alcabala tax is configured. This work concludes that in cases of nullity, resolution or rescission there is no legal justification to deny the refund of the paid alcabala tax, given that the consequence of those cases of inefficacy is to reverse the effects of the act or contract that originated the tax collection. Therefore, we consider that this retroactive effect conduces to the dissolution of the taxable event, so denying its refund contradicts the principle of contributory capacity.

KEYWORDS: alcabala, inefficacy, nullity, rescission, resolution, reform. 


\section{INTRODUCCIÓN}

$\mathrm{E}$ ntre los principios que guían la creación de tributos, aquel de capacidad contributiva reviste un particular interés, pues justifica el deber de contribución de los ciudadanos al gasto público. ${ }^{1}$ Todo cobro de impuestos debe fundamentarse en un indicio de capacidad contributiva, de lo contrario se ponen en riesgo los principios de igualdad, equidad, generalidad y no confiscatoriedad.

En el caso de impuestos asociados a la transferencia de bienes inmuebles, comprender la naturaleza y efectos del acto jurídico que antecede la enajenación resulta fundamental para una adecuada conceptualización del respectivo impuesto y, en particular, de su hecho generador, especialmente si se toma en consideración que el hecho generador constituye el elemento de partida de todo tributo, por lo que su debida determinación y comprensión son imprescindibles para asegurar un régimen tributario adecuado, preciso y fundamentado en el principio de capacidad contributiva.

Es en este punto que se percibe una inevitable coerción entre dos importantes ramas del Derecho: el Derecho Civil y el Derecho Tributario. Es importante que los efectos de la terminación e ineficacia de los contratos sean debidamente correlacionados con el hecho generador a fin de asegurar que el cobro de impuestos mantenga la justificación que le dio origen.

En el caso del impuesto de alcabala, tanto el actual art. 529 del Cootad como el art. 353 de su antecesora, la Ley Orgánica de Régimen Municipal² disponen, de manera sorpresiva, que no procede la devolución del impuesto pagado en los casos de reforma, nulidad, resolución o rescisión de los actos o contratos. Esta disposición invita a cuestionar si en estos casos existe una justificación para negar la devolución del impuesto pagado, tomando en consideración que el efecto de estas figuras es, precisamente, retrotraer los efectos del acto jurídico al momento previo al de su celebración.

En este contexto, el propósito del presente trabajo es analizar la referida disposición para determinar si en dichos supuestos de ineficacia se configura el hecho generador, a la luz del principio de capacidad contributiva y, por tanto, resulta procedente desconocer la devolución del impuesto. Este trabajo se centra exclusivamente en la imposibilidad de devolución a los contratantes, es decir, no se estudiará el caso en el cual se ve comprometido el pago del impuesto efectuado por la parte contractual a quien la reforma, nulidad, resolución o rescisión de otro contrato le afecta indirectamente.

1. Eddy De la Guerra, El deber de contribución al gasto público (Ciudad de México: Porrúa, 2018).

2. Tras la Codificación de la Ley Orgánica de Régimen Municipal, publicada en el Suplemento del Registro Oficial n. ${ }^{\circ} 159$ de 5 de diciembre de 2005, dicho artículo devino en el art. 346. 
Para abordar la problemática planteada, en primer lugar se analizará el hecho generador y su importancia en la justificación del tributo. Posteriormente se efectuará una breve introducción al hecho generador del impuesto de alcabala en el régimen jurídico ecuatoriano. Sobre la base de ello se analizará el art. 529 del Cootad, para finalmente presentar las conclusiones sobre la interrogante objeto de este trabajo.

\section{EL HECHO GENERADOR Y SU IMPORTANCIA}

\section{EN LA JUSTIFICACIÓN DEL TRIBUTO}

Para analizar el alcance del art. 529 del Cootad, es necesario resaltar la importancia del hecho generador como elemento configurativo de todo tributo, así como analizar su vinculación con el principio de capacidad contributiva. Ello debido a que ambos elementos constituyen un eje primordial para analizar la imposibilidad de solicitar la devolución del impuesto de alcabala en los casos previstos en el artículo motivo de este análisis.

\section{El hecho generador como elemento configurativo del tributo}

La obligación tributaria nace con la configuración del hecho generador. ${ }^{3}$ En la doctrina se ha definido el hecho generador como "el presupuesto de hecho previsto por la ley para que se configure el tributo, el cual, una vez cumplido, da nacimiento a la obligación tributaria". ${ }^{4}$ Este hecho generador es "el conjunto de presupuestos abstractos contenidos en las normas tributarias materiales y cuya concreta concurrencia [...] provoca determinadas consecuencias jurídicas". 5

El Código Tributario ecuatoriano ha definido el hecho generador de manera similar. En su art. 16 prescribe que "se entiende por hecho generador al presupuesto establecido por la ley para configurar cada tributo", ${ }^{6}$ mientras que su artículo 18 establece que "la obligación tributaria nace cuando se realiza el presupuesto establecido por la ley para configurar el tributo"?

3. Dino Jarach, El hecho imponible: teoria general del Derecho Tributario sustantivo, 3. a ed. (Buenos Aires: Abeledo Perrot, 1982), 73.

4. Alejandro Altamirano, Derecho tributario: teoría general (Buenos Aires: Marcial Pons, 2012 ), 343.

5. Albert Hensel, Derecho Tributario (Madrid: Marcial Pons, 2005), 154, 162.

6. Ecuador, Código Tributario, Registro Oficial 30, Suplemento, 14 de junio de 2005, art. 16.

7. Ibíd., art. 18. 
La relevancia del hecho generador como elemento configurativo del tributo está dada por la naturaleza misma de la obligación tributaria. Dado que la obligación tributaria es de carácter ex lege, a diferencia de las obligaciones que encuentran su origen en la voluntad de las partes, es fundamental que la ley defina claramente cuál será el supuesto que dé nacimiento a esta obligación. ${ }^{8}$

El hecho generador es un delimitador de la realidad, por cuanto "cuando se diseña el tributo, el legislador coge, de los múltiples hechos y actos a su disposición, aquellos que serán objetos del tributo". ${ }^{9}$ También se considera que el hecho generador reconoce una determinada capacidad contributiva, pues esta constituye "un dato objetivo del supuesto de hecho que será considerado por el legislador al momento de elaborar la obligación tributaria". ${ }^{10}$

Si bien el hecho generador es eminentemente jurídico, al ser este el elemento configurativo del tributo, toma en cuenta aspectos económicos para determinar, de manera adecuada, qué situaciones o actuaciones de los individuos estarán sujetas a tributos. Por ende, como se explicará en la siguiente sección, el hecho generador debe constituir una expresión de capacidad económica del destinatario de la norma.

\section{El hecho generador y su vinculación con el principio de capacidad contributiva}

El art. 300 de la Constitución de la República del Ecuador señala que el régimen tributario se regirá, entre otros, por el principio de generalidad. ${ }^{11} \mathrm{Al}$ respecto cabe señalar que "[con base en el] principio de generalidad que se deriva del principio de igualdad, todos los ciudadanos están obligados a concurrir en el sostenimiento de las cargas públicas, pero [en la medida en la que] tengan la necesaria capacidad contributiva puesta de manifiesto en los hechos tipificados por la ley". ${ }^{12}$

El principio de capacidad contributiva constituye uno de los pilares del Derecho Tributario. ${ }^{13}$ Esta capacidad es "una 'aptitud' efectiva del contribuyente para ser suje-

8. Jarach, El hecho imponible, 73.

9. Altamirano, Derecho tributario, 346.

10. Ibíd.

11. Ecuador, Constitución de la República del Ecuador, Registro Oficial 449, 20 de octubre de 2009, art. 300. Énfasis añadido.

12. Gerardo Novoa Herrera, "El principio de capacidad contributiva". Derecho y sociedad, n. ${ }^{\circ} 27$ (2006), 103. Énfasis añadido. Esta cita es una paráfrasis que realiza el autor a la obra de César Landa Arroyo: "Los principios tributarios en la Constitución de 1993", en Temas de Derecho tributario y de Derecho público: libro homenaje a Armando Zolezzi Möller (Lima: Palestra Editores, 2006), 47.

13. Jarach, El hecho imponible, 85. Énfasis añadido. 
to pasivo de obligaciones tributarias, aptitud inherente a la presencia de hechos reveladores de riqueza (capacidad económica)". ${ }^{14}$

En definitiva, la existencia de un tributo y la correspondiente calificación de su hecho generador exigen que el legislador observe el principio de capacidad contributiva. Este principio constituye entonces una garantía para el contribuyente en la creación de impuestos y se presenta como un supuesto necesario para asegurar equidad en la tributación. Sobre la base de esta conceptualización, a continuación se analizarán los elementos configurativos del impuesto de alcabala en el régimen jurídico ecuatoriano.

\section{BREVE INTRODUCCIÓN AL HECHO GENERADOR DEL IMPUESTO DE ALCABALA EN EL RÉGIMEN JURÍDICO ACTUAL ECUATORIANO}

El impuesto de alcabala ${ }^{15}$ "se despliega con [...] ocasión de la transferencia y adquisición de derechos reales como los de propiedad, usufructo, uso y habitación sobre bienes inmuebles" ${ }^{\prime 1}$. El art. 527 del Cootad cataloga como objeto de este impuesto los actos jurídicos que contengan el traspaso de dominio de bienes inmuebles, recogidos en sus arts. 527 y 528. En consecuencia, "el hecho imponible del impuesto de alcabala ocurre con la realización del acto jurídico gravable, mas no con la inscripción en el registro de la propiedad; [la cual] de ninguna manera configura la obligación tributaria, misma que nació o se originó antes, precisamente cuando se realizó el acto o contrato (acto jurídico) objeto del gravamen". ${ }^{17}$

A pesar de ello, el impuesto se origina, en principio, con la celebración del acto, aunque en realidad el pago se realice inclusive antes de esta celebración, pues el artículo 537 del Cootad exige al notario verificar el pago antes de extender la respectiva escritura pública. Esta particularidad del impuesto de alcabala genera un desfase entre

14. Alberto Tarsitano, "El principio de capacidad contributiva. Un enfoque dogmático", en Estudios de derecho tributario constitucional e internacional, coords. Pasquale Pistone y Heleno Taveira (Buenos Aires: Depalma, 2005), 409.

15. En la legislación actual las normas que regulan el impuesto de alcabala constan en los arts. 527 a 537 del Cootad.

16. Juan Carlos Mogrovejo Jaramillo, "Impuestos locales a las transferencias de dominio de bienes inmuebles”, FORO: Revista de Derecho, n. ${ }^{\circ} 20$ (2013). Ver también: Marco Aguirre Apolo, Manual de Derecho tributario municipal (Quito: Municipio del Distrito Metropolitano de Quito, 1994); Felipe Iturralde Dávalos, Manual de Tributación Municipal (Quito: Municipio del Distrito Metropolitano de Quito, 1998).

17. César Montaño Galarza y Juan Carlos Mogrovejo Jaramillo, Derecho tributario municipal ecuatoriano: fundamentos y práctica (Quito: Universidad Andina Simón Bolívar, Sede Ecuador / Corporación Editora Nacional, 2014), 117. 
la manifestación efectiva de capacidad contributiva, la configuración del hecho generador y el pago del tributo, abriendo paso a un eminente riesgo de pago indebido.

Precisamente, el último inciso del art. 529 del Cootad señala: "si para celebrar la escritura pública del acto o contrato que cause el impuesto de alcabala, este hubiere sido pagado, pero el acto o contrato no se hubiere realizado, se tomará como pago indebido previa certificación del notario respectivo". ${ }^{18}$

Esta disposición reconoce que existe un supuesto de pago indebido en aquellos casos en los que no se llega a realizar el acto o contrato, lo cual se justifica debido a que en estos casos no se configuró el hecho generador. En sentencia de 16 de octubre de 2002, la Segunda Sala de lo Civil y Mercantil de la Corte Suprema de Justicia se refirió a la inexistencia del hecho generador por falta de suscripción del acto, en los siguientes términos:

se encuentra probado que por una negociación de compraventa de un bien raíz, que es de carácter civil, que no ha sido concluida, se ha pagado valores, por concepto de impuestos de alcabalas y de registro, sin que haya lugar a esa obligación de naturaleza tributaria, sin que cambie, la simple disposición al Departamento Financiero Municipal de devolverlos, y en atención a que nunca se produjo el hecho generador de la obligación tributaria. ${ }^{19}$

Estimamos que, así como se reconoce la devolución en los casos en los que se paga el tributo pese a no celebrarse el acto (por ser un caso de no sujeción), igualmente debería reconocerse en los supuestos en los que pese a celebrarse el acto, y con este configurarse el hecho generador, con posterioridad a tal configuración, los efectos del acto son retrotraídos. Ello debido a que este efecto retroactivo conlleva, por su naturaleza, la disolución del hecho generador, tal como se detallará después.

\section{Análisis del art. 529 del CoOtad: \\ SUPUESTOS DE NO DEVOLUCIÓN DEL IMPUESTO DE ALCABALA}

El Cootad en su art. 529 excluye la posibilidad de requerir la devolución del impuesto de alcabala en casos de reforma, nulidad, resolución y rescisión. Esta norma invita a cuestionarse si existe una justificación para negar tal devolución. En esta sección se realizará una introducción al problema jurídico que presenta el referido artículo. Para analizar dicha problemática se revisará en primer lugar el efecto contractual

18. Ecuador, Cootad, Registro Oficial 303, Suplemento, 19 de octubre de 2010, art. 529. Énfasis añadido.

19. Ecuador, Corte Suprema de Justicia, Segunda Sala de lo Civil y Mercantil, "Sentencia", en Expediente de casación n. ${ }^{\circ}$ 324-2002, 16 de octubre de 2002, Registro Oficial 12, 31 de enero de 2003. 
de la reforma, nulidad, resolución y rescisión, para finalmente estudiar estas hipótesis en relación con el hecho generador del impuesto de alcabala y determinar si resulta justificable la disposición del artículo 529 del Cootad.

\section{Introducción al problema jurídico}

El Cootad contiene una disposición que llama la atención acerca de la imposibilidad de solicitar "la devolución del impuesto que se haya pagado en los casos de reforma, nulidad, resolución o rescisión de los actos o contratos". ${ }^{20}$

Considerando que el impuesto de alcabala se configura con motivo de la celebración de actos jurídicos que contengan el traspaso de dominio de bienes inmuebles, resulta difícil dilucidar la razón por la cual el legislador ha considerado que este impuesto se entenderá causado, y por ende no podrá devolverse, incluso cuando han desaparecido las circunstancias constitutivas de su hecho generador, como ocurre cuando un acto o contrato es declarado nulo, resuelto o rescindido.

En la siguiente sección se explicará en qué consisten las referidas figuras, a fin de comprender su naturaleza jurídica y efectos. Posteriormente se expondrá su vinculación con el hecho generador del impuesto de alcabala, con la finalidad de analizar si en estos casos se justifica desconocer la devolución del impuesto pagado.

\section{El efecto contractual de la reforma, nulidad, resolución y rescisión de los contratos}

A continuación se realiza una breve reflexión acerca de la naturaleza jurídica de las figuras de la reforma, nulidad, resolución o rescisión de los actos o contratos.

\section{Reforma}

El principio de la autonomía de la voluntad privada permite a los contratantes convenir las condiciones de los negocios que celebran, e incluso modificarlas con

20. Ecuador, Cootad, art. 529. Esta disposición estuvo recogida también en el artículo 353 de la Ley Orgánica de Régimen Municipal y posteriormente en el artículo 346 de su Codificación, publicada en el Suplemento del Registro Oficial 159 de 5 de diciembre de 2005. De hecho, el impuesto de alcabala es el tributo con origen más antiguo, entre los gravámenes actualmente vigentes, al haber sido creado en 1591 y aplicado en la Real Audiencia de Quito a partir del 10 de mayo de 1593. Ver también: Montaño Galarza y Mogrovejo Jaramillo, Derecho tributario municipal ecuatoriano: fundamentos y práctica, 166; y Eugenio Jaramillo Vega, Sinceramiento tributario (Quito: Corporación de Estudios y Publicaciones, 2008), 12. 
posterioridad a su celebración. Así, los contratantes tienen la potestad de reformar el contenido de los negocios que suscriben a través de la celebración de convenciones modificatorias.

\section{Nulidad}

La nulidad se configura cuando un negocio jurídico no cumple "los requisitos específicos que la ley prescribe con miras a la preservación del orden público y a la protección de los terceros y aun de los mismos agentes". ${ }^{21}$ Según Alessandri, "la nulidad es la sanción legal establecida para la omisión de los requisitos y formalidades que las leyes prescriben para el valor de un acto según su especie". ${ }^{22}$ En el ordenamiento jurídico ecuatoriano, tales requisitos de validez se encuentran previstos en el art. $1461^{23}$ del Código Civil y su ausencia se sanciona con nulidad, conforme lo prevé el art. 1697.

El inciso final del artículo 1697 contempla dos especies de nulidad: la absoluta y la relativa. Estos tipos de nulidad se configuran por causas distintas y tienen, además, un régimen jurídico diferenciado, en lo relativo a la legitimación activa para alegarla, la posibilidad de convalidación y el plazo de prescripción. Salvo por la diferenciación en sus causales, las demás diferencias entre estos regímenes no serán expuestas, al no ser parte del objeto de este trabajo.

La nulidad absoluta está contemplada en el art. 1698, el cual establece que son causales de nulidad absoluta: (i) el objeto ilícito; (ii) la causa ilícita; (iii) la omisión de algún requisito o formalidad que la ley prescriba para el valor de ciertos actos o contratos, en consideración a la naturaleza de ellos, y no a la calidad o estado de las personas que los ejecutan o acuerdan; y (iv) la incapacidad absoluta de quien celebra el negocio.

La nulidad relativa, en cambio, se configura por cualquier otra especie de vicio, distinto a los taxativamente enunciados en el artículo 1698, referente a las causales de nulidad absoluta. Según este mismo artículo, las causales de nulidad relativa dan derecho a la rescisión del acto o contrato. El Código Civil, a lo largo de su articulado, prevé una serie de hipótesis de nulidad, como, por ejemplo, la incapacidad relativa y los vicios del consentimiento (error, fuerza y dolo).

21. Guillermo Ospina Fernández y Eduardo Ospina Acosta, Teoría general del contrato y del negocio jurídico, 7. ${ }^{\mathrm{a}}$ ed. (Bogotá: Temis, 2016), 434.

22. Arturo Alessandri, La nulidad y la rescisión en el Derecho civil chileno (Santiago: Ediar Editores, 1949), 4.

23. Ecuador, Código Civil, Registro Oficial, Suplemento 46, 24 de junio de 2005, art. 1461. 
La declaratoria de nulidad, tanto absoluta como relativa, conlleva el deber de las partes de realizarse restituciones mutuas. El art. 1704 del Código Civil prescribe que "la nulidad pronunciada en sentencia que tiene fuerza de cosa juzgada, da a las partes derecho para ser restituidas al mismo estado en que se hallarían si no hubiese existido el acto o contrato nulo". ${ }^{24}$ No obstante, el Código Civil prevé ciertas excepciones al deber de restitución. Así, en los casos de anulación por objeto o causa ilícita, de acuerdo al art. 1704 del Código Civil, en concordancia con el artículo 1484, no procede la restitución respecto de lo "que se ha dado o pagado por un objeto o causa ilícita, a sabiendas" ${ }^{25}$ Existe también una limitación en cuanto a la nulidad por incapacidad, la cual está prevista en el art. 1705 del Código Civil. ${ }^{26}$

Sin perjuicio de ello, por regla general, el principal efecto de la declaratoria de nulidad consiste en retrotraer los efectos del negocio jurídico celebrado, a fin de que las partes se encuentren en el estado en el que se encontrarían si no lo hubiesen celebrado.

\section{Resolución}

La resolución es otra de las formas de ineficacia de los negocios jurídicos que se da por algunos motivos, como: (i) el avenimiento de la condición resolutoria ordinaria; y (ii) el ejercicio de la acción resolutoria.

La condición resolutoria consiste en un hecho futuro e incierto, del cual pende la extinción de una obligación y del derecho que le es correlativo. "La consecuencia del cumplimiento de la condición resolutoria es que los derechos y situaciones jurídicas se extinguen (perdiéndose para su titular), en tanto que los actos jurídicos se tornan ineficaces". ${ }^{27}$

A la condición resolutoria se le da el nombre de "ordinaria" cuando ha sido pactada por las partes y consiste en cualquier hecho al que las partes han acordado supeditar la vigencia de un derecho u obligación. Una vez verificada la condición resolutoria ordinaria pactada por las partes, la resolución se verifica ipso facto.

Existe también una tipología de condición resolutoria que se entiende incorporada en todos los contratos bilaterales, contemplada en el art. 1505 del Código Civil, la cual recibe el nombre de "tácita". Esta condición implica que, de no cumplirse lo pactado

\footnotetext{
24. Ibíd., art. 1704.

25. Ibíd., art. 1484.

26. Ibíd., art. 1705. Este artículo dispone: "Si se declara nulo el contrato celebrado con una persona incapaz, $\sin$ los requisitos que la ley exige, el que contrató con ella no puede pedir restitución o reembolso de lo que gastó o pagó en virtud del contrato, sino en cuanto probare haberse hecho más rica con ello la persona incapaz". Énfasis añadido.

27. Federico Ossola, Obligaciones (Buenos Aires: Abeledo Perrot, 2016), 194.
} 
por uno de los contratantes, el otro podrá pedir, a su arbitrio, la resolución o el cumplimiento forzoso del contrato; en ambos casos, con indemnización de perjuicios. La condición resolutoria tácita otorga a uno de los contratantes, frente al incumplimiento del otro, un derecho alternativo potestativo, que le permite pedir la resolución del contrato o exigir su cumplimiento forzado. De optar el contratante por solicitar la resolución del contrato, debe hacerlo a través de la acción resolutoria, por cuanto esta no opera ipso facto y debe ser declarada judicialmente.

Así, la resolución es el efecto del avenimiento de la condición resolutoria ordinaria pactada por las partes, o de una declaración judicial que puede darse como consecuencia del ejercicio de la acción resolutoria por parte de un contratante. En ambos casos, cumplida la condición resolutoria, operan las restituciones mutuas, ${ }^{28}$ por lo que la resolución tiene un efecto esencialmente retroactivo.

\section{Rescisión}

La rescisión es una forma de ineficacia que en nuestro ordenamiento jurídico ha sido asimilada con la nulidad relativa. Así lo prescribe el art. 1698, al señalar que los vicios que producen nulidad relativa dan derecho a la rescisión del acto o contrato. Dicha afirmación no es del todo precisa, pues la rescisión es una modalidad de ineficacia de contratos que han sido celebrados válidamente, pero que han perdido su eficacia por circunstancias ajenas a los requisitos de validez, como la lesión enorme, el fraude pauliano o la inoficiosa donación. Sin perjuicio de esta precisión, para efectos de este trabajo, lo relevante es resaltar que el resultado de la rescisión consiste igualmente en retrotraer los efectos del negocio jurídico celebrado, por lo cual su análisis dentro de la siguiente sección se enmarca en aquel de nulidad.

\section{Vinculación entre la reforma, nulidad, rescisión y resolución de los contratos y el hecho generador del impuesto de alcabala}

A continuación, se analizará si se justifica la disposición del art. 529 del Cootad, respecto a la imposibilidad de devolver el impuesto en los casos de reforma, nulidad y rescisión y resolución de los actos o contratos.

28. Ecuador, Código Civil, art. 1503. 


\section{Reforma}

Los supuestos de reforma del contrato implican una modificación a los términos en los que fue originalmente pactado. En principio esta situación no tiene mayor incidencia en el hecho generador del tributo ni en la manifestación de capacidad contributiva que lo justifica. Ello debido a que la reforma al contrato no se traduce en su desvanecimiento.

Sin perjuicio de ello, el tercer inciso del art. 529 del Cootad dispone que "la reforma de los actos o contratos causará derechos de alcabala solamente cuando hubiere aumento de la cuantía más alta y el impuesto se calculará únicamente sobre la diferencia". ${ }^{29}$ Esta disposición resulta plenamente coherente, pero insuficiente.

De conformidad con el art. 532 del Cootad, la base imponible del impuesto de alcabala es el valor contractual del acto cuya celebración genera el impuesto. Sin embargo, si este valor fuere inferior al avalúo catastral de la propiedad objeto de la transferencia de dominio, se empleará el valor del avalúo como base imponible. En consecuencia, por regla general la base imponible del impuesto de alcabala se compone del valor de la transferencia, salvo que este sea menor al avalúo catastral. Por lo tanto, si originalmente el impuesto se fijó sobre la base del avalúo, resulta lógico que, ante el aumento en la cuantía del contrato, se reliquide el impuesto sobre la nueva base imponible a fin de recaudar el valor restante.

No obstante, llama la atención que se limite esta posibilidad "solamente" cuando existe un aumento del valor contractual. Bien podría darse el caso de que el impuesto se hubiese calculado inicialmente sobre la base del valor contractual, por ser este superior al avalúo. De ser así, al reducirse la cuantía del contrato, resulta de igual forma necesaria una reliquidación del impuesto, de suerte que los sujetos pasivos estén en la posibilidad de solicitar la devolución de lo pagado en exceso.

En consecuencia, únicamente se justifica que la reforma del contrato no genere un derecho de devolución del tributo en favor de los sujetos pasivos cuando (i) la reforma no versa sobre el precio; o (ii) cuando, versando sobre el precio, la aplicación de la nueva base imponible genere un impuesto a pagar igual o mayor al pagado inicialmente.

No se cuestiona que, en los casos de reforma, el hecho generador, configurado inicialmente, persista, sin embargo, se estima necesario que la norma permita ajustar la base imponible tanto a favor del contribuyente como de la Administración Tributaria. En cambio, en los casos a ser estudiados a continuación es necesario enfocar el análisis

29. Ecuador, Cootad, art. 529. 
en si es adecuado afirmar que, en dichos supuestos, pese a originalmente haberse configurado el hecho generador, este perdura tras dispararse el efecto retroactivo que caracteriza a tales supuestos; $y$, por tanto, si en estos casos las normas que regulan el impuesto de alcabala son acordes a los principios constitucionales del régimen tributario.

\section{Nulidad y rescisión}

Queda claro que la nulidad, tanto absoluta como relativa (y la rescisión), se caracteriza por su efecto retroactivo. Esto implica que "la sentencia que declare la nulidad de un contrato debe producir el efecto de situar las cosas en el estado anterior a la negociación". ${ }^{30}$

Tomando en consideración que "[la nulidad ataca] el origen de la obligación, para destruir, con efecto retroactivo, el lazo jurídico que ella establecía", ${ }^{31}$ resulta inadecuado que el Cootad desconozca la devolución del impuesto pagado tras la anulación del acto traslaticio de dominio. Ello debido a que como consecuencia de la nulidad se despliega el efecto retroactivo y se extingue el acto que en su momento justificó la causación del impuesto.

El segundo inciso del art. 529 del Cootad dispone que:

se exceptúan de lo dispuesto en el inciso anterior [respecto a la imposibilidad de devolución del impuesto], los casos en que la nulidad fuere declarada por causas que no pudieron ser previstas por las partes; $y$, en el caso de nulidad del auto de adjudicación de los inmuebles que haya servido de base para el cobro del tributo. ${ }^{32}$

Este inciso da paso a la devolución del impuesto de alcabala (i) frente a la nulidad del auto de adjudicación de los inmuebles que sirvió como base para el cobro del tributo; y (ii) en los casos en los que la nulidad fue declarada por causas que no pudieron ser previstas por las partes.

En cuanto al primer caso, si el legislador da paso a la devolución ante la anulación del auto de adjudicación, entonces, ¿por qué impedirlo en otros supuestos de nulidad? Tanto en el caso de nulidad del auto de adjudicación como en los demás supuestos, el efecto es el mismo: su extinción con efecto retroactivo. En consecuencia, no se percibe una razón suficiente que permita diferenciar los casos de anulación del auto de

30. José Puig Brutau, Fundamentos de Derecho civil (Barcelona: Bosch, 1954), 320. Énfasis añadido.

31. Alfredo Barros Errazuruz, Curso de Derecho civil. Tratado de las Obligaciones en General (Santiago de Chile: Nacimento, 1932), 283.

32. Ecuador, Cootad, art. 529. 
adjudicación, de los demás supuestos de nulidad, ya que en ambos escenarios el efecto de la nulidad conlleva la disolución del acto que originalmente permitió la causación del impuesto.

Ante la extinción del acto, el hecho generador que en su momento se configuró se ve afectado y, por lo tanto, siempre y cuando se diluya también la manifestación de capacidad contributiva, debería originarse el derecho a la devolución de ese impuesto, indistintamente de si el acto anulado es un auto de adjudicación o un acto de otra naturaleza. La definición de si procede o no la devolución del tributo no debería atender a la naturaleza del acto anulado, sino a si, luego de la anulación, persiste o no una manifestación de capacidad contributiva del sujeto.

Por otro lado, en lo que concierne la segunda excepción, pareciera ser que el legislador considera que se justifica desconocer la devolución del impuesto cuando las partes pudieron prever las causas de nulidad. Esto permite suponer que la finalidad de impedir esta devolución se vincula a una especie de "sanción" al sujeto pasivo que conocía que el acto suscrito era susceptible de ser anulado.

$\mathrm{Al}$ respecto, es menester señalar que, en principio, toda causal de nulidad absoluta (objeto o causa ilícita, inobservancia de solemnidad esencial e incapacidad absoluta de quien celebra el negocio) debió ser conocida por las partes.

Por regla general, no existe justificación para que una de las partes alegue desconocimiento de una causal de objeto ilícito. Ello debido a que de acuerdo al art. 13 del Código Civil la ignorancia de la ley no excusa a ninguna persona. El art. 1478 del Código Civil señala que "hay objeto ilícito en todo lo que contraviene al Derecho Público Ecuatoriano", ${ }^{33}$ por lo tanto, al amparo de las normas antedichas, se presume de derecho que toda persona conoce de las causas que generarían que sus actos o contratos adolezcan de objeto ilícito. Lo mismo ocurre con la causa ilícita.

Con relación a la incapacidad absoluta de quien celebra el negocio o a las solemnidades que se requieren para su validez, la disposición del referido art. 13 impide que se pueda alegar desconocimiento de la necesidad de que un representante legal actúe en nombre de los incapaces absolutos para que estos puedan contratar, así como de la exigencia de cumplir las solemnidades previstas en la norma para la celebración de ciertos actos. Por lo cual resulta virtualmente imposible que en aplicación del art. 529 del Cootad se devuelva el impuesto pagado cuando el acto o contrato fue anulado por causales de incapacidad absoluta o inobservancia de alguna solemnidad.

Respecto a la falta de solemnidad como causal de nulidad, el art. 1740 del Código Civil prescribe que la venta de bienes raíces no se reputa perfecta ante la ley, mientras

33. Ecuador, Código Civil, art. 1478. 
no se ha otorgado escritura pública. Igual disposición contienen los art. 1416 y 1838 sobre la donación y la permuta de bienes inmuebles, respectivamente. La exigencia de escritura pública en cuanto a otros derechos reales constituidos sobre bienes inmuebles se encuentra a su vez en los arts. 717 para la servidumbre; 781 y 826 , para el usufructo y el uso y habitación; y 2311 para la hipoteca. Los supuestos de herencia de encuentran atados a las solemnidades del testamento, si lo hubiera, o de la partición y adjudicación.

De acuerdo al art. 527 del Cootad, "los notarios no podrán extender las antedichas escrituras, ni los registradores de la propiedad inscribirlas, sin que se les presenten los recibos de pago de las contribuciones principales y adicionales, debiéndose incorporar estos recibos a las escrituras", ${ }^{34}$ por ende, resulta improbable, por decir lo menos, que se dé un caso de nulidad absoluta por falta de solemnidad en el acto o contrato, que origine la devolución del impuesto; tomando en cuenta que este se paga conjuntamente con el cumplimiento de la solemnidad.

Ahora bien, para determinar si existe algún supuesto de nulidad relativa o rescisión, en el cual procedería la devolución del impuesto de alcabala se requiere determinar el alcance de la expresión "causas que no pudieron ser previstas por las partes". Si la referida norma exige que la causal haya sido imprevisible para ambas partes, entonces tampoco procedería en la mayoría de los casos de rescisión, ni en aquellos de nulidad relativa, pues en varios de estos supuestos, al menos una de las partes, aquella que no se ve afectada por el vicio (ya sea de nulidad o rescisión), conoce de su existencia.

No obstante, si la intención de la norma es habilitar la devolución del impuesto a la parte que desconocía del vicio, en este caso, ciertos supuestos de nulidad relativa permitirían al menos a una de las partes solicitar la devolución del impuesto por ella pagado. Sin embargo, la parte que conoció el vicio se vería imposibilitada a reclamar la devolución del impuesto pese a que, con la destrucción del acto, se desvirtúa la capacidad contributiva que en un principio justificó la causación y cobro del impuesto.

Este análisis permite reafirmar la suposición de que la intención de la disposición del art. 529 es "sancionar" de cierto modo al contratante que conocía la causal de nulidad. Ante ello cabe cuestionarse si esa es realmente la finalidad del Derecho Tributario, ¿se justifica desconocer la devolución de un tributo para reprender a un contratante que suscribió un acto viciado de nulidad; o ese tipo de consecuencias deben ser tratadas en el ámbito del Derecho Civil?

Además, es importante traer a colación que el hecho de conocer el vicio no justifica per se que se deba "sancionar" al sujeto (ni desde el ámbito tributario ni desde el ci-

34. Ecuador, Cootad, art. 527. 
vil), pues en ciertos tipos de vicio la persona que lo conoce es aquella afectada por él. Por ejemplo, en los casos de fuerza, la persona sobre quien esta se ejerce, claramente conoce del vicio al momento de prestar su consentimiento (forzado), pues al hacerlo está siendo sometida a un acto que le infunde "un justo temor de verse expuest[a] [...] a un mal irreparable y grave". ${ }^{35}$ Dicha persona, pese a conocer del vicio, es, a su vez, víctima de la fuerza. No obstante, bajo el criterio "sancionatorio" del segundo inciso del art. 529 del Cootad, el hecho de haber conocido el vicio no le permitiría solicitar la devolución del impuesto pagado, en caso de que el acto en el que consintió (sometido por la fuerza) fuere posteriormente anulado.

Así, consideramos que el reconocer o no la devolución del impuesto de alcabala en casos de nulidad (ya sea absoluta o relativa) no debería estar condicionado a si una de las partes conocía o no el vicio, sino a si, como consecuencia de la nulidad se despliegan efectos retroactivos que diluyen la capacidad contributiva que en principio se evidenció a través del acto anulado. Como se expuso anteriormente, la norma civil contempla ciertos casos en los que pese a la anulación del acto no habrá lugar a la restitución, que normalmente se despliega como consecuencia del efecto retroactivo. Por lo tanto, lo que podría justificar que en el ámbito tributario se desconozca el derecho a la devolución del tributo sería el hecho de que, pese a la anulación, persista la capacidad contributiva, por no haberse desplegado en su totalidad las restituciones mutuas propias de la nulidad.

\section{Resolución}

Mutatis mutandi, el análisis realizado respecto a la nulidad puede trasladarse al supuesto de resolución del contrato pues ambos casos tienen como consecuencia retrotraer los efectos del contrato al momento previo al de su celebración. Por lo tanto, en la resolución del contrato también se destruye el acto que en su momento justificó la causación del impuesto de alcabala.

\section{Crítica al art. 529 del Cootad}

Los efectos de la resolución, nulidad, rescisión e inclusive la resciliación deben ser correctamente articulados en el Derecho Tributario a fin de garantizar precisión en la tributación. Consideramos que es inadecuado que se desconozca la devolución del impuesto de alcabala pagado, aun cuando sustancialmente no persiste el hecho

35. Ecuador, Código Civil, art. 1472. 
generador. Si bien, con la celebración del acto, el hecho generador se configuró, posteriormente, con los efectos retroactivos de la resolución, nulidad o rescisión —según corresponda - este hecho generador se diluye.

Con dicha disolución debería proceder la devolución del tributo, pues el pago que originalmente fue debido (por haberse causado el tributo) se convierte en indebido, pues el tributo causado pierde su hecho generador y con ello muta hacia un caso de no sujeción.

En este contexto cabe referirse al art. 12 del modelo de Código Tributario del Centro Interamericano de Administraciones Tributarias, el cual prevé una (des)vinculación entre los efectos que un acto tiene en la configuración del hecho generador y aquellos que podría tener en otras ramas del Derecho. Este artículo dispone: "La obligación tributaria no será afectada por circunstancias relativas a la validez de los actos o a la naturaleza del objeto perseguido por las partes ni por los efectos que los hechos o actos gravados tengan en otras ramas jurídicas". ${ }^{36}$

En primera instancia, se podría considerar que esta norma avala de cierta forma la disposición del art. 529 del Cootad, pues parecería ser que la configuración del hecho generador debe ser analizada con independencia de los efectos que este acto pueda tener en otras ramas jurídicas, como el Derecho Civil. De hecho, el párrafo 1 de los comentarios a este artículo indica "una vez verificado ese presupuesto [hecho generador], el correspondiente tributo se hace exigible, sin que interese cualquier calificación del mismo". ${ }^{37}$

No obstante, es importante recordar que la (des)vinculación prevista en el art. 12 pretende evitar supuestos de elusión tributaria y no se trata de una norma que desconozca la necesidad de precautelar el principio de capacidad contributiva ni los elementos que caracterizan a supuestos de ineficacia en materia contractual, como lo son la anulación, rescisión o resolución.

En efecto, el tercer párrafo de los comentarios a este artículo es claro al señalar que "queda fuera de la regla establecida respecto a la subsistencia de la consecuencia tributaria de los actos, como podría ser de otra manera, los supuestos de anulación, rescisión o resolución de los actos jurídicos que da lugar a la obligación tributaria". ${ }^{38}$

El Tribunal Supremo de España sostuvo que el principio de capacidad contributiva "quiebra en aquellos impuestos en los que la capacidad económica gravada por el

36. Centro Interamericano de Administraciones Tributarias, Modelo de Código Tributario del CIAT, 2015, art. 12.

37. Ibíd., art. 44. Énfasis añadido.

38. Ibíd. 
tributo sea no ya potencial sino inexistente o ficticia". ${ }^{39}$ La nulidad, rescisión y resolución de los contratos inciden directamente en el hecho generador del impuesto de alcabala, el cual, si bien se configura en razón de la celebración del acto, se justifica en atención a los efectos que se desprenden — y perduran — de dicho acto. Desconocer aquello implica gravar una capacidad netamente ficticia, que deviene en inexistente una vez que se retrotraen los efectos del acto que en un principio motivó el cobro del impuesto.

\section{CONCLUSIONES}

El impuesto de alcabala tiene como hecho generador la celebración de ciertos actos jurídicos traslaticios de dominio de bienes inmuebles. Por ende, resulta evidente que la existencia y eficacia de un acto o contrato que conlleve la transferencia de dominio es un presupuesto necesario para que se configure este impuesto. A pesar de ello, nuestro ordenamiento jurídico contiene una problemática norma que genera que, en ciertos supuestos, el impuesto de alcabala sea cobrado incluso en ausencia de acto o contrato; esto es, en ausencia de un hecho generador.

El art. 529 del Cootad prescribe que no habrá lugar a la devolución del impuesto de alcabala que se haya pagado en los casos de reforma, nulidad, resolución o rescisión de los actos o contratos. Al respecto se evidencia que, en los casos de reforma de los términos del negocio, la disposición se encuentra, preliminarmente, justificada. La reforma únicamente consiste en una modificación de los términos del negocio; situación que, en principio, no tiene mayor incidencia sobre el hecho generador. No obstante, la disposición del Cootad es insuficiente por cuanto no es claro si procede la devolución parcial del impuesto en caso de que la reforma produzca una disminución en la cuantía del contrato. Aplicando la regla general del inciso primero del art. 529 del Cootad, los sujetos pasivos pagarían un impuesto sobre una base imponible mayor a la real, lo cual es cuestionable.

En casos de nulidad y resolución, la disposición que es objeto de análisis resulta sumamente problemática. Ambas figuras se caracterizan por su efecto retroactivo. La declaratoria de nulidad o resolución de un acto tiene como ineludible consecuencia el situar a las partes en el estado que se encontraban con anterioridad a su celebración. Por ende, el impuesto de alcabala generado por un acto que posteriormente es decla-

39. España Tribunal Supremo, "Sentencia n. ${ }^{\circ} 221 / 1992 ", 22$ de diciembre de 1992; "Sentencia n. ${ }^{\circ} 184 / 2000 "$, 19 de julio de 2000; "Sentencia n. ${ }^{\circ} 193 / 2004$ ", 4 de noviembre de 2004. Estas sentencias han sido citadas en Juan Martín Queralt et al., Curso de Derecho financiero y tributario (Madrid: Tecnos, 2014), 118. 
rado nulo o resuelto, pierde su hecho generador, en razón del efecto retroactivo que se deriva de tales declaraciones, por lo cual debería ser susceptible de devolución.

En conclusión, a nuestro criterio, no existe ninguna justificación en el marco del Derecho Tributario para desconocer la devolución del impuesto de alcabala pagado en supuestos de nulidad, rescisión, resolución o reforma (con las salvedades expuestas a lo largo de este trabajo). Al contrario, una vez que se retrotraen los efectos del acto o contrato que originó el cobro del impuesto, este adolece de sustancia en el hecho generador $y$, por tanto, negar su devolución contraviene el principio de capacidad contributiva.

Es necesario que esta disposición normativa sea reevaluada tomando en cuenta que el cobro de impuestos debe necesariamente encontrar su fundamento en un indicio de capacidad contributiva.

\section{BIBLIOGRAFÍA}

Aguirre Apolo, Marco. Manual de Derecho tributario municipal. Quito: Municipio del Distrito Metropolitano de Quito, 1994.

Alessandri, Arturo. La nulidad y la rescisión en el Derecho civil chileno. Santiago de Chile: Ediar, 1949.

Altamirano, Alejandro. Derecho tributario: teoría general. Buenos Aires: Marcial Pons, 2012.

Barros Errazuruz, Alfredo. Curso de Derecho civil. Tratado de las Obligaciones en General. Santiago de Chile: Nascimento, 1932.

Canosa Torrado, Fernando. La resolución de los contratos. Bogotá: Editorial Doctrina y Ley, 1993.

Castán Tobeñas, José. Derecho civil español, común y foral. Madrid: Reus, 2007.

Centro Interamericano de Administraciones Tributarias. Modelo de Código Tributario del CIAT. 2015.

De la Guerra, Eddy. El deber de contribución al gasto público. Ciudad de México: Porrúa, 2018.

Ecuador Corte Suprema de Justicia, Segunda Sala de lo Civil y Mercantil, "Sentencia”. En Expediente de casación $n .^{\circ}$ 324-2002. 16 de octubre de 2002. Registro Oficial 12, 31 de enero de 2003.

Ecuador. Codificación a la Ley Orgánica de Régimen Municipal. Registro Oficial 159, Suplemento, 5 de diciembre de 2005.

—. Código Civil. Registro Oficial 46, Suplemento, 24 de junio de 2005.

- Código Orgánico de Organización Territorial, Autonomía y Descentralización. Registro Oficial 303, Suplemento, 19 de octubre de 2010.

—. Código Tributario. Registro Oficial 30, Suplemento, 14 de junio de 2005. 
-. Constitución de la República del Ecuador. Registro Oficial 449, 20 de octubre de 2009.

—. Ley Orgánica de Régimen Municipal. Registro Oficial 331, Suplemento, 15 de octubre de 1971.

España. Tribunal Supremo. "Sentencia n. ${ }^{\circ} 221 / 1992 ” . ~ 22$ de diciembre de 1992.

—. "Sentencia n. ${ }^{\circ} 184 / 2000 " . ~ 19$ de julio de 2000.

—. "Sentencia n. 193/2004". 4 de noviembre de 2004.

García Vizcaíno, Catalina. Derecho Tributario. Buenos Aires: Depalma, 1999.

Gómez, Alfredo. La equidad tributaria: su correcta aplicación en México. Ciudad de México: Corporativo Reyes Mora Advisors, 2012.

Hensel, Albert. Derecho tributario. Madrid: Marcial Pons, 2005.

Ibáñez, Carlos Miguel. Resolución por incumplimiento. Buenos Aires: Astrea, 2003.

Iturralde Dávalos, Felipe. Manual de Tributación Municipal. Quito: Municipio del Distrito Metropolitano de Quito, 1998.

Jarach, Dino. El hecho imponible: teoría general del Derecho tributario sustantivo. Buenos Aires: Abeledo Perrot, 1982.

—. Estudios de Derecho tributario. Buenos Aires: Cima Profesional, 1998.

—. Finanzas públicas y derecho tributario. Buenos Aires: Abeledo Perrot, 1996.

Jaramillo Vega, Eugenio. Sinceramiento tributario. Quito: Corporación de Estudios y Publicaciones, 2008.

Josserand, Louis. Derecho Civil, tomo II, vol. 1. Buenos Aires: Bosch, 1950.

Lozano Serrano, Carmelo. Exenciones tributarias y derechos adquiridos. Madrid: Tecnos, 1988.

Merino Jara, Isaac, dir. Derecho financiero y tributario: parte general, 5. ${ }^{\mathrm{a}}$ ed. Madrid: Tecnos, 2015.

Mogrovejo Jaramillo, Juan Carlos. "Impuestos locales a las transferencias de dominio de bienes inmuebles". FORO: Revista de Derecho, n. ${ }^{\circ} 20$ (2014).

Montaño Galarza, César, y Juan Carlos Mogrovejo Jaramillo. Derecho Tributario Municipal Ecuatoriano: fundamentos y práctica. Quito: Universidad Andina Simón Bolívar, Sede Ecuador / Corporación Editora Nacional, 2014.

Novoa Herrera, Gerardo. "El principio de capacidad contributiva". Derecho y Sociedad, n. ${ }^{\circ}$ 27 (2006).

Ospina Fernández, Guillermo, y Eduardo Ospina Acosta. Teoría general del contrato y del negocio jurídico, 7. a ed. Bogotá: Temis, 2016.

Ossola, Federico. Obligaciones. Buenos Aires: Abeledo Perrot, 2016.

Pérez de Ayala, José Luis, y Miguel Pérez de Ayala Becerril. Fundamentos de Derecho Tributario. Madrid: Editoriales de Derecho Reunidas, 1998.

Puig Brutau, José. Fundamentos de Derecho Civil. Barcelona: Bosch, 1954.

Queralt, Juan Martín, et al. Curso de Derecho Financiero y Tributario. Madrid: Tecnos, 2014. 
Queralt, Juan Martín, Carmelo Lozano Serrano y Francisco Poveda Blanco. Derecho Tributa-

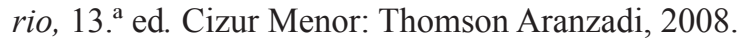

Sánchez-Medal Urquízar, José. La resolución de los contratos por incumplimiento. Ciudad de México: Porrúa, 1998.

Tarsitano, Alberto. "El principio de capacidad contributiva. Un enfoque dogmático". En Estudios de derecho tributario constitucional e internacional, coordinado por Pasquale Pistone y Heleno Taveira. Buenos Aires: Depalma, 2005.

- . "El principio de capacidad contributiva como fundamento de la constitución financiera una visión doctrinaria y jurisprudencial”. Derecho \& Sociedad, n. 43 (2014): 119-28.

Troya Jaramillo, José Vicente. Manual de Derecho tributario. Quito: Corporación de Estudios y Publicaciones, 2014.

Villegas, Héctor. Curso de Finanzas, Derecho Financiero y Tributario, 8. a ed. Buenos Aires: Astrea, 2003. 